\title{
Habitual Joint Dislocations and Recurrent Multiple Hernias: An Unusual Connective Tissue Disease?
}

\author{
Claudio Spinelli*, Jessica Piscioneri, Leonardo Rossi, Silvia Strambi and Concetta Liloia \\ Department of Surgical, Medical, Molecular pathology and of the Critical Area, Chair of Pediatric Surgery, University of Pisa, Italy
}

\begin{abstract}
Purpose: Joint laxity and hernia defects are two well-defined conditions that are rarely described in association in literature. The purpose of this study is to describe a peculiar case of connective tissue disorder, not yet defined, whose features are habitual joint dislocations associated with recurrent and multiple hernias.

Methods: This is an unusual case regarding a 22 years old male adult, who presented shoulder, patellar, mandibular habitual joint dislocations associated with groin, femoral, epigastric, umbilical, spigelian and lumbar hernias. His phenotype, consisting of tall stature and joint laxity, recalls a similar-marfanoid habitus.

Results: Marfan Syndrome, Ehlers-Danlos syndrome, MEN-2B were excluded by specific assessments. The aspecific clinical features of the patient do not consent the identification of an exact diagnosis.

Conclusion: This medical case, characterized by joint hypermobility and multiple recurrent hernias, probably consists in an unacknowledged peculiar case of connective tissue disorder. Further investigations and identification of subjects with similar features could be surely useful to diagnostic research and definitive characterization of patient's disease.
\end{abstract}

Keywords: Connective tissue disease; Connective tissue disorder; Joint dislocations; Joint hypermobility; Multiple hernias

\section{Introduction}

The purpose of this study is to show a peculiar case of connective tissue disorder, not specifically defined, whose features are habitual joint dislocations associated with recurrent and multiple hernias. This case is outstanding because, according to evaluations and data from scientific literature, a so well documented description about the connection between the two phenomena does not exist at the moment. Searches on the subject have not been successful in order to define the clinical features of the patient in a specific disorder. Studies have pointed out a considerable number of diseases with distinguishing features including sometimes joint hypermobility with multiple hernias. Among these rare disorders Marfan Syndrome (OMIM 154700) [1], Ehlers-Danlos Syndrome (OMIM 130000) [2], MEN 2-B [3], Shprintzen-Goldberg Syndrome (OMIM 182212) [4], Loeys- Dietz Syndrome (OMIM 190181) [5], Cutis Laxa (OMIM 219200) [6], Arterial Tortuosity Syndrome (OMIM 208030) [7], Larsen Syndrome (OMIM 609192) [8] are described. Most of these diseases comprise a connective tissue disorder but none of them answers properly to our diagnostic question because of their specific characteristics, which are not present in this patient.

\section{Case Report}

The patient came to our attention at the age of 22 for evaluation of his clinical features. Family history was remarkable: his mother showed the similar-marfanoid habitus [9] described for her son and the same has undergone operations for groin and femoral hernias. Surgical repairs for groin and spigelian hernias were also performed in patient's grandfather. No further familiarity is described and the subject is onlychild. Patient's history documents adenoidectomy and appendicectomy followed by a long succession of surgical corrections for recurrent joint dislocations and multiple hernias, as reported in Table 1.

Surgical treatments were carried out in 8 years, for a total of 29 operations (15 for joint dislocations and 14 for hernia defects). Despite the correctness of surgical procedure, dislocations and hernia defects occur again maybe due to the underlying connective tissue disorder since no precipitating factors which could be involved in their development were described.

When examined, patient's height was $181.8 \mathrm{~cm}$, weight $90 \mathrm{~kg}$ (BMI: 27.23- overweight in accordance with Cole [10] criteria). His height and weight have always been superior to the age groups. Height and joint laxity concur to the definition of a similar marfanoid-habitus.

Development indices were normal (testicles in scrotum, normal penis lenght). Generalized adiposity, valgus knee and even shoulder joint dislocation were described during the examination. No hand hypermobility was found in the physical examination of the patient.

Clinical and instrumental evaluations have been done to define patient's disease. Doppler echocardiography was performed at first to evaluate cardiac function and to exclude Marfan Syndrome, which was suspected because of similar-marfanoid habitus. The examination documented normal aortic bottom and valve according to dimensions, morphology and kinetics [aortic botton: $3.3 \mathrm{~cm}$ (normal range 2.5-3.5 $\mathrm{cm}$ ); aortic valve diameter: $2.0 \mathrm{~cm}$ ]. Genetic analysis for the research of FBN-1 mutation (chromosome 15q21.1, OMIM 134797) resulted negative. MEN 2B was considered subsequently as a possible diagnosis for the patient. Hormonal profile for thyroid, parathyroid and adrenal function was normal. Further genetic evaluations for the research of RET gene mutation (10q11.2, OMIM 164761) were negative. No mucocutaneous, neuromuscular, cardiovascular, gastrointestinal and genitourinary involvements as well as genetic anomalies (COL1A1OMIM 120150-, COL1A2-OMIM 120160-, COL3A1-OMIM 120180-,

*Corresponding author: Claudio Spinelli, Department of Surgical, Medical, Molecular pathology and of the Critical Area, Chair of Pediatric Surgery, University of Pisa, Italy, Tel: +39 050 997702; Fax: +39 050 997707; E-mail: c.spinelli@dc.med.unipi.it

Received July 03, 2015; Accepted July 25, 2015; Published July 31, 2015

Citation: Spinelli C, Piscioneri J, Rossi L, Strambi S, Liloia C (2015) Habitual Joint Dislocations and Recurrent Multiple Hernias: An Unusual Connective Tissue Disease? J Clin Case Rep 5: 563. doi:10.4172/2165-7920.1000563

Copyright: ( $\odot 2015$ Spinelli C, et al. This is an open-access article distributed under the terms of the Creative Commons Attribution License, which permits unrestricted use, distribution, and reproduction in any medium, provided the original author and source are credited. 


\begin{tabular}{|c|c|c|}
\hline Age & Pathology & Treatment \\
\hline 14 & - $\quad$ Shoulder dislocation (right and left) & Capsular shift \\
\hline 16 & - $\quad$ Recurrent shoulder dislocation (right -2- and left) & Capsular shift \\
\hline 17 & - $\quad$ Patella dislocation (left) & Knee joint replacement \\
\hline 18 & - $\quad$ Recurrent shoulder dislocation (right and left) & Capsular shift \\
\hline 19 & $\begin{array}{ll}- & \text { Groin hernia (left) } \\
- & \text { Recurrent shoulder dislocation (right and left) }\end{array}$ & $\begin{array}{ll}- & \text { Surgical repair } \\
- & \text { Capsular-shift }\end{array}$ \\
\hline \multirow{4}{*}{20} & - Epigastric hernia & Surgical repair \\
\hline & - Umbilical hernia & Surgical repair \\
\hline & - $\quad$ Recurrent femoral hernia (right) & Surgical repair \\
\hline & - $\quad$ Recurrent groin hernia (right and left) & Surgical repair \\
\hline 21 & $\begin{array}{ll}\text { - } & \text { Spigelian hernia (right and left) } \\
\text { - } & \text { Mandibular dislocation }\end{array}$ & $\begin{array}{l}\text { Surgical repair } \\
\text { Joint reduction }\end{array}$ \\
\hline 22 & - $\quad$ Grynfeltt hernia (right and left) & Surgical repair \\
\hline
\end{tabular}

Table 1: Surgical treatment chronology.

COL5A1-OMIM 120215-, COL5A2-OMIM 120190-) were described so that Ehlers-Danlos Syndrome was excluded.

Histological analysis of synovium obtained during surgery was performed: it showed morphological abnormalities (synovial membrane with papillary pattern associated with edematous connective tissue) but none of them was specific for a particular disorder.

\section{Discussion}

The patient's clinical history shows a close connection between two different conditions: habitual joint dislocations and multiple-recurrent hernias.

Early studies have always favored the view that joint hypermobility merely represents the upper end of a Gaussian distribution of the normal joint range of movement, defined by Beighton criteria. That view is now challenged by the notion that this variety of hypermobility may represent a departure from "normality" [9].

When hypermobility becomes symptomatic with manifestations as dislocation, instability and displacement, the "joint hypermobility syndrome" (JHS) exists [11]. This feature is included among different forms of Heritable Disorders of Connective Tissue (HCTDs) such as Marfan Syndrome, Ehlers-Danlos Syndrome and Osteogenesi Imperfecta [9]. The role of the connective tissue is extremely documented for the development of joint hypermobility: genetic defects of collagen synthesis are involved in the formation of lax joints which are likely to be less stable and are generally more susceptible to the effects of trauma [11,12].

Hernias are anatomic defects that need surgical treatment. Classically, inguinal hernias are considered to be the result of a multifactorial process linking predisposing anatomical and dynamical factors, such as enlargement of the weak inguinal area and increased intra-abdominal pressure but now, there is evidence that hernia formation and recurrence are linked to abnormal metabolism of connective tissue $[13,14]$. Diseases of responsible genes for the synthesis and regulation of tissue components as collagen, extracellular matrix and elastic fibers, are involved in the development of hernias [14-16]. The connection between joint laxity and hernia defects is still today debated $[13,17]$. The attempt to establish a direct association between joint hypermobility and hernias (even if limited to groin area) appears in a recent study by Cevik et al. [18]. The results show that in children with hypermobility syndrome and inguinal hernias the prolidase activity and oxidative stress in tissue samples are increased and are related to collagen tissue damage and turnover.
Because of his phenotype and joint laxity, first suspicion for our patient was Marfan syndrome but his clinical features did not satisfy the diagnostic Ghent criteria for the pathology. These consist of osteoarticular diseases (the only found in our case) associated with ocular, cardiovascular, tegumental and respiratory anomalies [19].

Although recurrent inguinal hernia is included in the diagnostic criteria for MFS, there are few reports of the incidence of inguinal hernia in MFS [15]. According to these reasons and to the negative result for genetic anomalies in FBN-1 gene, Marfan Syndrome diagnosis was excluded for our patient. MEN2B [3] was considered and excluded according to the absence of medullary thyroid carcinoma, pheochromocytoma, ganglioneuromatosis, and a distinct marfanoid habitus. Genetic researches for RET mutations; confirm that MEN$2 \mathrm{~b}$ was not responsible for patient's clinical feature. Because of the joint laxity associated with hernias, Ehlers- Danlos Syndrome [2] was also suspected for our case. No cutaneous, vascular, neurological, ocular anomalies were found as well as genetic anomalies, so EDS was excluded. Other diagnostic hypothesis for the dealt case was Shprintzen-Goldberg Syndrome [4]: this rare disease is characterized by marfanoid habitus, joint laxity and occasional hernias (groin, umbilical) but there are no grounds for supporting this suspicion on accont of craniosynostosis which dominates the clinical feature and is not described in our patient. Loeys- Dietz syndrome [5], Cutis Laxa [6], Arterial Tortuosity Syndrome [7] and Larsen Syndrome [8] were also excluded for their specific clinical features that are not included in patient's disease.

\section{Conclusions}

According to the scientific literature and the exclusion of the aforesaid pathologies, we can affirm that this medical case, characterized by joint hypermobility and multiple recurrent hernias, probably consists in a connective tissue disorder, not yet clearly defined as the unsuccessful investigations show. The attempt to catalogue the patient's disease in a specific pathology is so far vain since clinical, genetic and instrumental data exclude our suppositions. Further investigations and identification of subjects with similar features could be surely useful to diagnostic research and definitive characterization of patient's diseases.

All procedures followed were in accordance with the ethical standards of the responsible committee on human experimentation (institutional and national) and with the Helsinki Declaration of 1975, as revised in 2008 Informed consent was obtained from all individual participants included in the study. 
Citation: Spinelli C, Piscioneri J, Rossi L, Strambi S, Liloia C (2015) Habitual Joint Dislocations and Recurrent Multiple Hernias: An Unusual Connective Tissue Disease? J Clin Case Rep 5: 563. doi:10.4172/2165-7920.1000563

\section{References}

1. Yuan SM, Jing H (2010) Marfan's syndrome: an overview. Sao Paulo Med J 128: $360-366$.

2. Callewaert B, Malfait F, Loeys B, De Paepe A (2008) Ehlers-Danlos syndromes and Marfan syndrome. Best Pract Res Clin Rheumatol 22: 165-189.

3. Spinelli C, Di Giacomo M, Costanzo S, Elisei R, Miccoli P (2010) Role of RET codonic mutations in the surgical management of medullary thyroid carcinoma in pediatric age multiple endocrine neoplasm type 2 syndromes. J Pediatr Surg 45: $1610-1616$

4. Au PY, Racher HE, Graham JM, Kramer N, Lowry RB, et al. (2014) De novo exon 1 missense mutations of SKI and Shprintzen-Goldberg syndrome: two new cases and a clinical review. Am J Med Genet A 3: 676-684.

5. Van Laer L, Dietz H, Loeys B (2014) Loeys-Dietz syndrome. Adv Exp Med Biol 802: 95-105

6. Gardeitchik T, Mohamed M, Fischer B, Lammens M, Lefeber D, et al. (2014) Clinical and biochemical features guiding the diagnostics in neurometabolic cutis laxa. Eur J Hum Genet 22: 888-895.

7. Franceschini P, Guala A, Licata D, Di Cara G, Franceschini D (2000) Arterial tortuosity syndrome. Am J Med Genet 91: 141-143.

8. Sajnani AK, Yiu CK, King NM (2010) Larsen syndrome: a review of the literature and case report. Spec Care Dentist 30: 255-260.

9. Malfait F, Hakim AJ, De Paepe A, Grahame R (2006) The genetic basis of the joint hypermobility syndromes. Rheumatology $45: 502-527$.

10. Cole TJ, Bellizzi MC, Flegal KM, Dietz WH (2000) Establishing a standard definition for child overweight and obesity worldwide: international survey. BMJ 320: 1240-1243.

11. Grahame R (1999) Joint hypermobility and genetic collagen disorders: are they related? Arch Dis Child 80: 188-191.

12. Jobling R, D'Souza R, Baker N, Lara-Corrales I, Mendoza-Londono R, et al (2014) The collagenopathies: review of clinical phenotypes and molecular correlations. Curr Rheumatol Rep 16: 013-0394.

13. Pans A, Albert A (2003) Joint mobility in adult patients with groin hernias. Hernia 7: $21-24$.

14. Henriksen NA, Yadete DH, Sorensen LT, Agren MS, Jorgensen LN (2011) Connective tissue alteration in abdominal wall hernia. Br J Surg 98: 210-219.

15. Barnett C, Langer JC, Hinek A, Bradley TJ, Chitayat D (2009) Looking past the lump: genetic aspects of inguinal hernia in children. J Pediatr Surg 44: 1423-1431.

16. Henriksen NA, Mortensen JH, Sorensen LT, Bay-Jensen AC, Agren MS et al. (2015) The collagen turnover profile is altered in patients with inguinal and incisional hernia. Surgery 157: 312-321.

17. Nazem M, Mottaghi P, Hoseini A, Khodadadi HA (2013) Benign joint hypermobility syndrome among children with inguinal hernia. J Res Med Sci 18: 904-945.

18. Cevik M, Yazgan P, Aksoy N (2014) Evaluation of antioxidative/oxidative status and prolidase parameters in cases of inguinal hernia with joint hypermobility syndrome. Hernia 18: 849-853.

19. Loeys BL, Dietz HC, Braverman AC, Callewaert BL, De Backer J, et al. (2010) The revised Ghent nosology for the Marfan syndrome. J Med Genet 47: 476485 